Çukurova Üniversitesi Mühendislik Mimarlık Fakültesi Dergisi, 35(1), ss. 105-114, Mart 2020

Çukurova University Journal of the Faculty of Engineering and Architecture, 35(1), pp. 105-114, March 2020

\title{
Madencilik Sektöründe İş Sağlığı ve Güvenliği Yönetimi için Veri Entegrasyonu Uygulaması
}

\author{
Mustafa ERKAYAOĞLU ${ }^{* 1}$
}

${ }^{1}$ Orta Doğu Teknik Üniversitesi, Mühendislik Fakültesi, Maden Mühendisliği Bölümü, Ankara

Geliş tarihi: 04.02.2020 Kabul tarihi: 15.05.2020

\section{$\ddot{\mathbf{O} z}$}

Madencilik endüstrisi, iş sağlığı ve güvenliği açısından değerlendirildiğinde, farklı mühendislik alanlarını ve bunlara bağlı riskleri kapsamaktadır. Günümüzde, teknoloji alanında yaşanan gelişmeler, madencilik endüstrisini mevcut donanım ve yazılımlar aracılığıyla, üretim, ekipmanların bakım/onarım durumu, maliyet, çevresel koşullar ve en önemlisi iş sağlığı ve güvenliği konusunda, veri toplayabilecek duruma getirmiş̧ir. Bu çalışmada, iş sağlığı ve güvenliği ile ilgili farklı kaynaklardan elde edilen verilerin entegre edildiği bir uygulama sunulmaktadır. Veri entegrasyonu uygulamasında kullanılan, vaka çalışması sonucunda ekipman sağlığı ile ilgili güvensiz durum kayıtlarının, farklı ekipler ve taşıma işlemleri için incelenebileceği ortaya konmuştur. Özellikle vardiya başlangıçlarının, iş sağlı̆̆ı ve güvenliği ile ilgili olayların yaşanabileceği bir zaman aralı̆̆ı olduğu belirlenmiştir. Veri görselleştirmesi, analiz kabiliyeti açısından sınırlı olup, günümüzde kullanılan bilgi görselleri ve modern görselleştirme araçlarına rağmen, veri içerisindeki yapılar karmaşık hale gelebilmektedir. Belirli olayların sebepleri incelenirken, veri madenciliği gibi daha sistematik yöntemlerin kullanılması önerilmektedir.

Anahtar Kelimeler: Açık ocak madenciliği, Veri ambarı, Veri entegrasyonu, İşs sağlığı ve güvenliği

\section{A Data Integration Application for Occupational Health and Safety Management in the Mining Industry}

\begin{abstract}
Mining is an industry that covers various engineering disciplines and the related risks to them in terms of occupational health and safety. Recent technological improvements in available hardware and software solutions led the mining industry to be able to collect data related to productivity, machine maintenance, costs, environmental conditions, and most importantly, occupational health and safety. This study introduces a data integration application for analyzing safety related records by using multiple data sources. The case study presented in the study revealed that the unsafe events related to machine health could be analyzed for different operator crews based on haulage type. It is observed that the beginning of a shift is a potential duration where occupational health and safety related events occur. Patterns within data by visual interpretation have limited analytics capability and can become overwhelmingly complex, even with info-graphics and modern graphic tools. It is suggested to follow a systematic methodology such as data mining to find patterns for the causes of specific events.
\end{abstract}

Keywords: Surface mining, Data warehouse, Data integration, Occupational health and safety

*Sorumlu yazar (Corresponding author): Mustafa ERKAYAOĞLU, emustafa@metu.edu.tr 


\section{GíRiş}

Madencilik endüstrisi, iş sağlığı ve güvenliği ile çeşitli mühendislik disiplinlerinin harmanlandığı ve bunlara ilişkin olası tüm riskleri kapsayan bir endüstridir. Çoğu sanayide ve süreçte olduğu gibi madencilik sektöründe yapılan iş sağlığı ve güvenliği yönetimi, ilgili süreçlerin, olayların ve risklerin sayısal olarak ölçülebilmesi temeline dayanmaktadır. Günümüzde, mevcut donanımlar ve kullanılan yazılımlardaki teknolojik gelişmeler, madencilik endüstrisinin verimlilik, ekipman sağlığı, maliyetler, çevre koşulları ve en önemlisi de iş sağlı̆̆ ve güvenliği ile ilgili verileri toplayabilmesine imkan sağlamıştır.

Madencilikte yaygın olarak kullanılan veri toplama sistemleri, entegre sistemler olmamakla birlikte, farkl1 tiplerdeki verileri toplayabilme kapasitesine sahiptir ve genellikle sadece belirli amaçlar için bilgi sağlamaktadırlar. İş sağlığı ve güvenliği kavramı ise tüm süreçler ile ilgili ve ilişkili olduğu için operasyonel verileri toplayan sistemlerin ortak bir iş sağlığı ve güvenliği hedefi için bütünleştirilmesi gerekmektedir. Fakat tüm sisteme entegre olmaları ve daha ileri seviye analiz işlemleri yapabilmeleri için uygun bir altyapıya sahip olmaları önemlidir. Bazı araştırmacılar, iş sağlığ1 ve güvenliği yönetimi için veri entegrasyonu yöntemlerinden yararlanarak sistem altyapısının avantajlarını belirlemişlerdir [1,2] . Benzer altyapıya sahip veri sistemleri tarafindan toplanan veriler, birbirlerinden tamamiyla bağımsız olarak değerlendirilemez. Bu duruma örnek olarak, ekipman sağlığı ile ilgili bilgilerin izlenmesi verilebilir. Ekipman sağlığının takibi, ekipmanın çalışma koşullarının izlendiği ve önceden belirlenmiş olan bir eşik değerin aşılması durumunda, alarmın devreye girmesi gibi bir dizi önlemi kapsamaktadır. Bu sistem, normalde bakım planlama işlemlerini geliştirmek için kullanılmakta olup, ekipman operatörünün sürüş davranışlarını izlemek için de kullanılabilmektedir. Bununla birlikte, bir operatörün, bir ekipmanı kullanması sırasında dikkatli veya art niyetli davranması da üretkenlik veya güvenlik kavramları üzerinde etkili olabilmektedir.
İş sağlığı ve güvenliği verileri, bu konudaki risklerin proaktif bir şekilde izlenmesini ve modellenmesini sağlayabilmektedir. Bu tip veriler, diğer veri kaynaklarıyla entegre olabilmekte ve risklerin verimli bir şekilde yönetilmesinde önemli bir rol oynamaktadırlar. İş sağlığı ve güvenliği verilerinin entegre olabileceği diğer veri kaynaklarına örnek olarak da güvenlik kültürü programı ölçütleri, eğitim geçmişi, operatör performansı ve ekipman sağlığı gibi konular verilebilmektedir. Veri setleri, hali hazırda mevcut olan çeşitli raporlama araçları ve/veya elektronik tablolar kümesi aracılığıyla, zaten kullanılabilir durumdadırlar. Aynı zamanda, kullanıcı tarafindan elle yapılacak olan basit kopyala/yapışıtır işlemleri ile elektronik tablolara entegre edilebilirler. Modern bilgi teknolojilerinden aldığı güç ile 'Büyük Veri' olarak isimlendirilen bu veri kaynakları, analiz ve modellemeyi kolaylaştırmak için özel olarak tasarlanmıș tek bir ortama detaylı bir şekilde bütünleştirilebilir.

Uzmanlar, verileri bir arada daha kolay analiz edebilmek için yalnızca hedeflenen riske özgü veri setlerini değil, sahada mevcut tüm verileri raporlayarak ve değerlendirerek de iş sağlığ güvenliği risklerini tanımlayabilirler. Risk modellerinin geliştirilmesinin ardından veri akışları üzerinde gerçek zamanlı veri madenciliği uygulamaları geliştirilebilmektedir. $\mathrm{Bu}$ sayede gerçek zamanlı veya gerçek zamanlıya yakın bir şekilde iş sağlığı ve güvenliği ölçülmeye ve izlenmeye başlanabilmektedir.

Modern maden işletmelerinin iş sağlı̆̆ güvenliği verilerini entegre ve analiz etme yöntemlerindeki amaçları ve uygulamaları arasında ciddi farklılıklar vardır. Veri konsolidasyonu ve toplama işlemi, çoğu zaman birden fazla kaynaktan gelen verilerin aylık bölüm istatistiklerine göre toplanarak analiz edilmeden sadece rapor edildiği elektronik tablolarda gerçekleşir. $\mathrm{Bu}$ raporlar, veri işlemenin bitiş noktası olmamakla birlikte, daha ileri analiz yöntemleri ve problemleri çözmeyi sağlayacak sorular sormanın bir yolu olarak değerlendirilmektedir. 
Madencilik şirketlerindeki iş sağlığı ve güvenliği uzmanlarının çoğunluğu, veri madenciliği veya veri işleme konusunda uzman kişiler değillerdir. Esas görev tanımları gereğince, belirlenen yönergelere uyumluluğu denetlemek ve eğitim programları yoluyla, daha az kaza veya olay kaydı oluşmasını hedeflemektedirler.

Uzmanların incelediği iş sağlığı ve güvenliği veri kümelerinin çoğu, elektronik tablolar, MS Access veri tabanları veya kısmen de kurumsal kaynak yönetimi sistem verileri gibi çeşitli kaynaklarda depolanmaktadır. Madencilikte iş sağlığı ve güvenliği bölümü, ekipman kayıtları, gecikme kayıtları, verimlilik kayıtları, denetim kalitesi, bakım/onarım iş emirleri, eğitim kayıtları ve hatta çevresel dalgalanmalar gibi alternatif veri setlerine nadiren erişir veya bunları değerlendirir; çünkü bu kayıtlar diğer bölümler tarafından çoğu zaman veri tabanlarında toplanır ve farklı veri yapılarında saklanır.

Madenlerde karar verme rolüne sahip kullanıcıların tüm detayları içeren gerçek verilere ulaşması ve bu verileri veri madenciliği teknikleri ile değerlendirerek anlamlandırabilmeleri, halen daha araştırılmamış, iki çok önemli araştırma alanı ve konusudur. Maden verileri, hiçbir zaman tamamıyla erişime açık olmamakla birlikte, bu konuda çalışan araştırmacılarla nadiren paylaşılmaktadır. Ülkemizde çok az sayıda maden işletmesinde, çeşitli veri kaynaklarının hem geçmiş, hem de gerçek zamanlı veri akışları kullanılarak, birleştirilmesine veya incelenmesine izin veren bir veri altyapısı vardır. Veri madenciliğinde, bu amaçla kullanılan veri setinin yanı sıra, teknolojinin de derinlemesine anlaşılması gerekmektedir.

Günümüze kadar, büyük ölçekli veri madenciliği için geliştirilen çoğu uygulama ulusal güvenlik, çevrimiçi ticaret, havacılık [3] ve güncel olarak hasta merkezli sonuçlar için tıbbi verilere odaklanmıştır. Madenlerdeki iş sağlığı ve güvenliği ile ilgili veriler ile yapılan veri madenciliği uygulamalarına odaklanan sınırlı sayıda çalışma bulunmaktadır.
Dessureault ve arkadaşları [4] madenlerdeki iş sağlığı ve güvenliği verileri üzerinde veri madenciliği uygulama potansiyelini araştırmak amaciyla ABD'de bulunan İş Sağlığı ve Güvenliği Ulusal Enstitüsü (NIOSH) veri seti üzerinde çalışmışlardır. $\mathrm{Bu}$ çalışmada, veri tabanının yapısını modernize ederek, veri tabanını gelişmiş analitik işlemler için kullanılabilir hale getirmek amacıyla, veri ambarı metodolojisi izlenmiştir. Ayrıca veri madenciliği için mevcut olan yazılımlar, çeşitli araştırmacılar tarafından iş kazalarının nedenlerini belirlemek amaciyla da kullanılmıştır [5-9]. Gerassis ve arkadaşları [10], yapay zekâ kullanarak, İspanya'daki madenlerde yaşanmış iş kazaları veri tabanını analiz etmiştir. $\mathrm{Bu}$ çalışmada, farklı iş kazaları için bilinmeyen ilişkilerin veri madenciliği teknikleri kullanılarak araştırılabileceği ifade edilmiştir. Madencilik endüstrisindeki diğer veri madenciliği uygulamaları ise operasyonel veriler [11], bakım [12], ekipman performansi, havalandırma [13] ve diğer alanlara odaklanmıştır.

İş sağlığ 1 ve güvenliği yönetiminde, veri madenciliği tekniklerinden ve çeşitli kaynaklardan veri toplayan sistemlerden yararlanan yeni bir yaklaşıma ihtiyaç bulunmaktadır. $\mathrm{Bu}$ sistemler, çalışan, ekipman, saha durumları gibi koşulları izleyerek veri toplayabilmektedir. Madenciliğin gelişmiş olduğu ülkelerde, resmi kuruluşlar da veri toplama ve değerlendirme için izlenecek metodoloji/yol hakkında önerilerde bulunabilmektedir [14,15]. Herhangi bir veri entegrasyonu veya veri madenciliği uygulaması, öncelikle madencilik endüstrisindeki mevcut verilerin özelliklerinin iyi anlaşılmasını gerektirmektedir.

\section{MADENCILIKKTE VERI TIPLERİ}

Madenlerdeki iş sağlığı ve güvenliği yönetimini daha güncel hale getirmek ve veri madenciliği uygulamalarına yönlendirmek için çeşitli yeniliklerin uygulanması gerekmektedir. Bu değişimi anlamak için endüstride kullanılan veri yapılarının türlerini anlamak gerekir. $\mathrm{Bu}$ veri yapısı türleri yapılandırılmış veriler, yarı 
yapılandırılmış veriler ve yapılandırılmamış veriler olarak üç başlık altında incelenebilir.

\section{1. İlişkisel Veri tabanları ve Veri Ambarı - Yapılandırılmış Veri}

İlişkisel veriler, veri tabanlarında depolanan tabloları kullanarak yapılan veri toplama sürecinin standart yoludur.

$\mathrm{Bu}$ veriler, madenlerde toplanan verilerin birçoğunu, özellikle de tüm geleneksel iş sağlığ ve güvenliğiyle birlikte üretim kayıtlarının da çoğunu kapsamaktadır. Bu veriler, son kullanıcı tarafindan Microsoft (MS) Access, MS SQL Server veya SAP gibi, kurumsal sistemlerdeki elektronik tablolara ve ilişkisel veri tabanlarına aktarılır ve/veya depolanır. Bazı madencilik şirketleri, gerekli bilişim altyapısı yatırımlarını gerçekleştirerek, raporlama ve veri analizi çalışmaları için bütünleşik bir sisteme bağlı tek bir veri tabanından yararlanabilmektedir. Bu sistem, birçok farklı kaynaktan gelen verileri entegre eden hem geçmiş verileri, hem de gerçek zamanlı verileri toplayan merkezi bir havuzdur. Bu tip veri ambarları aracılığıyla yapılan performans analizinin, geçmiş veriler için uygulanmasına "İş Zekâsı”, gerçek zamanlı veriler için uygulanması ise "Operasyonel Zekâ" olarak tanımlanmaktadır.

\subsection{Süreç Verileri-Yarı Yapılandırılmış Veriler}

Hem kontrol etkileşimleri, hem de endüstriyel süreç boyunca koşullar, ilişkisel bir veri tabanına düzenli olarak örnekleme yoluyla veya Historian adı verilen, özel endüstriyel veri depolama araçları yoluyla kaydedilebilir ve saklanabilir. Süreç verileri veya endüstriyel veriler, genellikle gömülü sistemler olarak adlandırılan, gerçek zamanlı endüstriyel süreçlerden gelen sensör veya kontrol verilerinin toplanması ile elde edilmektedir. Programlanabilir Lojik Kontrolör (PLC), Veri Tabanlı Kontrol ve Gözetleme Sistemi (SCADA) endüstriyel süreci izleyen ve operatörler yardımı ile endüstriyel sistemleri kontrol eden ve takip eden bilgisayarlardır. Kontrol etkileşimleri ile beraber, süreç boyunca oluşan koşullar, ilişkisel bir veri tabanına düzenli olarak örnekleme yoluyla veya Historian vasitasıyla kaydedilebilir ve saklanabilir. Örneğin, yeraltı kömür madenlerinde, Karbon Monoksit sensörlerini, konveyör bantlarını, elektrik motorlarını ve diğer analog sinyalleri izlemek için farklı izleme sistemleri kullanılmaktadır. $\mathrm{Bu}$ sinyal ölçümleri, sanal etiketler altında kaydedilir. Örneğin, belirli bir konveyörün motorundan dakikada bir alınan amper değeri, etiketler altında kaydedilir. Verilerin bu süreç görünümleri, gerçek zamanlı eğilimleri veya farklı nicel analog değişkenler arasındaki ilişkileri bulmak için uygun olmaktadır. Giderek daha da erişilebilir olan bu süreç verilerinden önemli bilgiler elde etmek mümkün olmaktadır. Örneğin, teknoloji ve onun sağladığı veriler sayesinde birbirine bağlı karmaşık sistemlerin ölçülmesi ve izlenmesini baz alan büyük ölçekli bir güç şebekesi için hem uzun vadeli, hem de kısa vadeli kararların verilebildiği gitgide büyüyen bir "akıllı şebeke" hareketinin oluşturulması sağlanabilmektedir.

Süreç verileri, ölçümün anlamının büyük bir kısmının etiketin/ölçümün detaylı açıklaması ile süreç içerisindeki önerileri içeren etiketin meta verileriyle ilgili olduğu durumda temel olarak etiketleme verileri olarak kabul edilebilir. $\mathrm{Bu}$ nedenle, işlem verileri yalnızca kısmen yapılandırılmış veya yarı yapılandırılmış olarak değerlendirilebilir. Örneğin, konveyör motorundan okunan amper değeri tek bir etiket olmasına rağmen, bu etiket, maden işletmesinin belirli bir bölgesinde çalışan bir konveyörü temsil edebilmektedir ve okunan amper değeri konveyör torkunu ifade ettiği için basit bir dönüşüm ile amper değeri, newtonmetre değerine çevrilerek konveyör hızı bulunabilmektedir.

\subsection{Yapılandırılmamış Veriler}

Yapılandırılmamış veriler, büyük ölçüde sosyal medya ve web posta trafiği (Gmail gibi hizmet kullanıcıları) nedeniyle, en hızlı büyüyen veri biçimidir. Önceden tanımlanmış bir veri modeline sahip olmayan (ilişkisel bir modele kıyasla belirli bir veri tablosu ile özel olarak ilgili olmayan) veya önceden tanımlanmış bir formatta düzenlenmemiş bilgileri ifade eder. Yapılandırılmamış veriler, genellikle metinseldir, ancak tarihler veya sayısal 
değerler gibi veri türlerini de içerebilmektedir. Yapılandırılmamış verilere örnek olarak; sağlık kayıtları, ses verileri, etiket için çok az meta verinin bulunduğu yerlerdeki analog veriler, resimler ve web sayfaları, e-posta veya iş sağlığ ve güvenliği olayı açıklaması gibi dokümanların gövdesinde bulunan metinler gösterilebilir. $\mathrm{Bu}$ veriler, çeşitli yapılarda olabilmektedir; örneğin, iş sağlığı ve güvenliği ile ilgili bir olayın açıklaması, kazaya karışan madencinin/operatörün ve ilgili ekipmanın adı, yaralanmanın niteliği ve ciddiyeti gibi yapılandırılmış verilerle birlikte, açıkça tanımlanmış kategorilere sahiplerdir. Yapılandırılmamış verilere bir başka örnek ise çevrim içi reklam veren yapılar olarak gösterilebilir. Bu altyapılar, potansiyel müşterileri tanımlamak için yapılandırılmamış verileri kullanırlar [16]. Diğer bir örnek ise gönderilen epostaların taranarak içeriğinde bahsi geçen konularda göndericiye ve alıcıya uygun reklamlar sağlanmasıdır. $\mathrm{Bu}$ şekilde yapılan metin madenciliği sayesinde, bir güvenlik olayı veya iş emri, yeni kategoriler veya ilişkiler tanımlanabilmektedir.

İş sağlığı ve güvenliği ile ilgili konularda, veri madenciliği uygulamak için aşağıda sıralanan kaynaklardan alınan veriler kullanılabilir.

\section{İș Sağlığı ve Güvenliği \& Eğitim}

- İş sağlığı ve güvenliği olayı: olayın gerçekleştiği zaman, yer, operatör, bölüm, makina, vb. veriler - İş sağlığ́ ve güvenliği olay incelemesi: tam metin açıklama, zaman, yer, operatör, bölüm, makina, vb. veriler

- İş sağlığı ve güvenliği olayı ile alakalı yapılan faaliyetlerin izlenmesi

- Yaralanmalar nedeniyle oluşan sağlık kayıtları ve maliyetler (kişisel verileri koruma yönergeleri kapsamında gizli tutulmak durumundadır)

- İhlaller, hem resmi, hem de dâhili kayıtlar

- Eğitim kayıtları

\section{Ekipman Bakım-Onarım \& Maliyetler}

- Detaylı arıza raporları

- Muhasebe sistemi kayitları (kurumsal sistem); tüm iş emri maliyetleri ve iş emri açıklaması da dâhil olmak üzere detaylar (özellikle hasar bilgisi eklenirken önemlidir).

- Ekipman sağlık verileri, ekipman alarmları, özel uyarılar ve geçmiş analog sinyaller kayıtları

\section{Güvenlik Kültürü}

- İş yeri denetim kayıtları

- Güvenlik teşviklerine bağlılık / uyum

- İs gözlem kayıtları: açıklamalar, takip eylemleri

- Dijital süpervizör kontrol listeleri ve 'vardiya geçişi' raporları (not: bilinen riskler, vardiya geçişinde genellikle bir vardiyadan diğerine iletilir).

- Yorgunluk izleme sistemi: göz izleme kamera sistemleri, geçerli dikkat dağıtıcı sürücü olayları, yanlış pozitifler, vb.

\section{Üretim}

- Saatlik çalışanların işe başlama ve iși bitiriş zamanlarının yer aldığı kartlarda bulunan RFID tabanlı sistemin bir parçası olan sanal delikli kart verileri

- Maden İzleme Sistemleri: tüm yeraltı ekipmanlarını (konveyör, vinç, fanlar) ve sensör kayıtlarını (Karbon Monoksit monitörleri) içeren işlem verileri

- Çeşitli üretim izleme sistemlerinden elde edilen tüm üretim kayıtları

- Her günün her saatini hesaba katan üretim bilgileri ve makinanın ne yaptığını içeren durum kodları ile birlikte kamyon/kepçe sevk sistemleri gibi ilişkisel sistemler de dâhil olmak üzere çeşitli üretim izleme sistemlerindeki tüm üretim kayıtları

- Dozer, çekme kepçe (dragline) ve delici ekipman izleme dâhil olmak üzere, yüksek hassasiyetli GPS izleme sistem verileri. $\mathrm{Bu}$ sistem verileri, aynı zamanda operatör becerisi ve titizliği hakkında da bilgi verebilir.

- Elle tutulan vardiya tabanlı üretim ve gecikme kayitları

- Operatör, konum (GPS), alarm sirasındaki durum ve aktivite gibi bilgiler dâhil olmak üzere makina sağlığı alarmları

Tüm sonuçlar analiz edilirken operatörlerin, maden işletmelerinin ve şirket bilgilerinin gizliliği korunmalıdır. Tüm ana ekipmanlar, birden fazla 
sistem tarafindan izlenebilir. Her saniye hesaba katıldığı ve GPS hareketleri izlendiği için çeşitli sistemlerde toplu olarak saatlik yüzlerce kayıt üretilebilir. Veri kümelerinin potansiyel olarak entegre edilebilmesi amaciyla belirlenebildiği, entegre edilebildiği ve veri madenciliğine hazır hale getirebildiği ortak bir özellikler grubu oluşturmak için veriler mümkün olduğunda kurumsal veri ambarının bir parçası olarak sunulmalıdir.

\section{VERİ UYGULAMASI}

Modern maden işletmeleri, sahada çalışan ekipmanlar hakkında detaylı veri toplayabilecek sistemlerle donatılmaktadır. Rogers ve arkadaşları [17], çalışmalarında maden işletmelerinin günümüzde nesnelerin interneti, iş zekâsı ve mobil cihazlarla bilgi işleme gibi alanlar için geliştirilen sistemlere yatırım yapmaları gerektiğini belirtmiştir. Bu sistemlerin etkin şekilde çalışması için güvenilir ve esnek bir veri altyapısına ihtiyaç duyulmaktadır. Maden işletmelerinde, sistematik veri altyapısına ihtiyaç duyulan birçok alan bulunur. Haas ve arkadaşları [18], maden işletmelerinin iş sağlı̆̆ 1 ve güvenliğ politikalarında tanımlanan amaç ve hedefler doğrultusunda hangi iletişim araçlarının kullanıldığını araștırmıștır. Şirketlerin kurumsal karne uygulamalarında, öncü ve gecikmeli göstergeleri birlikte kullanarak iş güvenliği yönetimini en etkin şekilde kullanmaları önerilmektedir. Chunmin ve arkadaşları [19], dijital maden olarak tanımladıkları geleceğin madeni konsepti için veri, işlem ve uygulama olarak ayrı seviyelerden oluşan katmanlı bir altyapı önermiştir. Bu altyapıya veri sağlayan dağınık veri kaynaklarından güvenilir sonuçlar elde edilmesi için en önemli unsurun veri entegrasyonu olduğu vurgulanmıştır. Veri entegrasyonunun madencilik faaliyetlerinde karar verme sürecine destek olarak kullanılabileceğini belirten Kahraman ve Dessureault [20], geliştirilen uygulamaların süreç değişimi ile uyumlu şekilde uygulanması gerektiğine dikkat çekmiştir.

$\mathrm{Bu}$ çalışma kapsamında yürütülen veri entegrasyonu uygulamasında, ABD'de bulunan bir açık ocak kömür madeninde gerçekleşen güvenli olmayan durum kayıtlarından yararlanılmıştır. Uygulamada 3 farklı veri kaynağı MS SQL Server yazılımları kullanılarak entegre edilip görselleştirilerek farklı örüntüler araştırılmıştır. Şekil 1'de, maden işletmesinin kullandığ 1 iş sağlığ ve güvenliği yönetim sisteminde bulunan veriler özetlenmiştir.

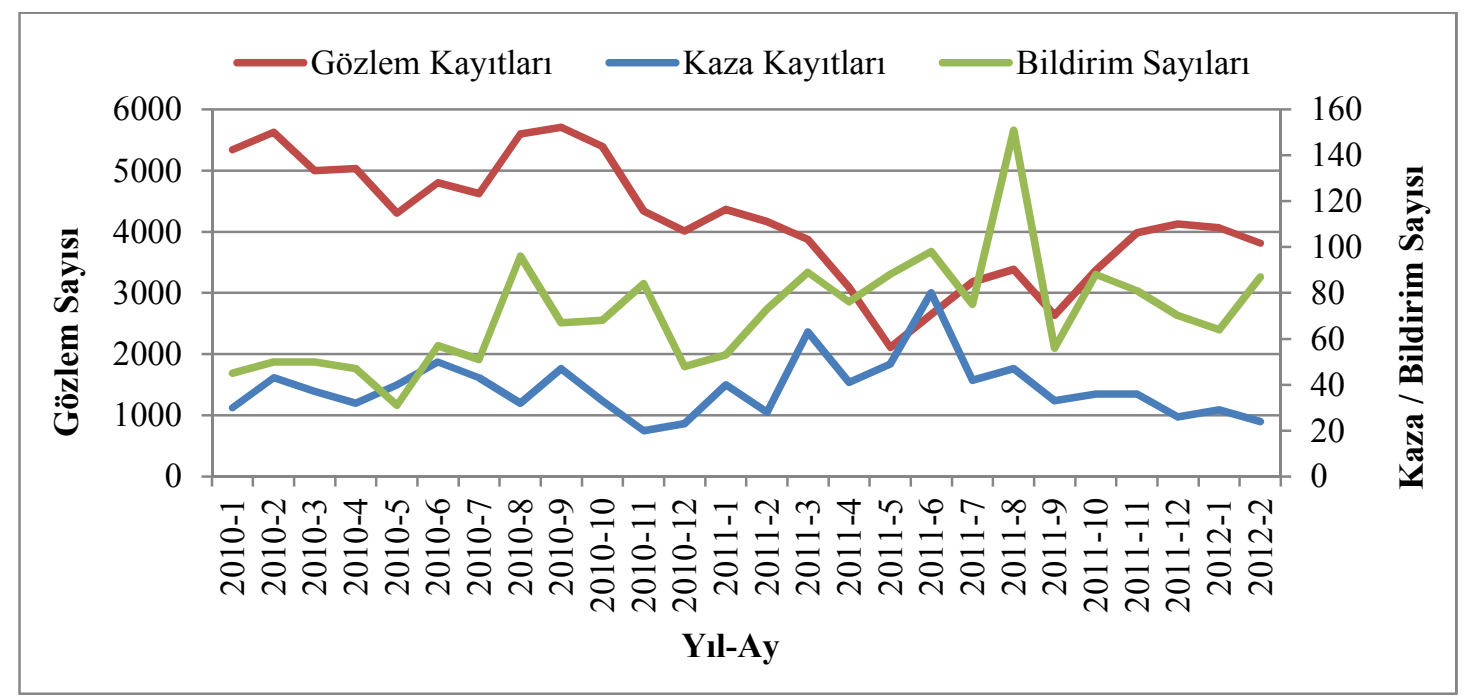

Şekil 1. İş sağlığı ve güvenliği yönetim sistemindeki kayıtların dağılımı 
MS SQL Server yazılımı bir veri tabanı yönetim sistemi olmakla birlikte raporlama ve analiz amacıyla kullanılabilen ek özelliklere sahiptir [21]. Çalışmada yürütülen veri analizi ve veri madenciliği uygulamaları, MS SQL Server Analysis Services (SSAS) kullanılarak tamamlanmıştır. Veri analizi için kullanılan temel araç OLAP küpleridir ve bütünleşik şekilde veriyi çok boyutlu olarak incelemeye yarayan bu araçlara MS Excel aracılığıyla Pivot tabloları olarak erişim sağlamak mümkündür [22]. Yaklaşık iki yıllık bir süre zarfında kayıt altına alınan, iş sağlığı ve güvenliği ile ilgili gözlem, kaza ve bildirim sayıları incelendiğinde belirli dönemlerde daha detaylı incelenmesi gereken durumların gerçekleştiği görülmektedir. Ancak bu veriyi, yılın ayları olarak tanımlanan bir zaman çözünürlüğünde başka bir veri sistemi ile entegre etmeden anlamlandırmak mümkün olmamaktadır.
Yararlanılan veri kaynaklarından olan filo yönetim sistemi, işletmede kullanılan ekipmanların üretim sırasında geçen sürelerini çalışan ekipler, ekipmanlar ve farklı zaman aralıkları için sağlayabilmektedir. $\mathrm{Bu}$ sistem tarafindan kaydedilen veri, ilişkisel niteliktedir ve çok miktarda detaylı ekipman bilgisi içerir. Filo yönetim sisteminin verisi, kayıt aralığı ve nitelik olarak değerlendirildiğinde, hem gerçek zamanlı, hem de geçmişe dönük şekilde farklı uygulamalar aracılığıyla kullanılabilir. Bu veriye entegre edilen diğer bir veri kaynağı, ekipman sağlığ kayıtları olmuştur. Ekipmanların kullanıldıkları süre boyunca, gerçekleşen güvensiz olay ve durumlar, zaman ve operatör gibi farklı veri boyutlarında Şekil 2'de görüldüğü üzere, analiz edilebilmektedir.

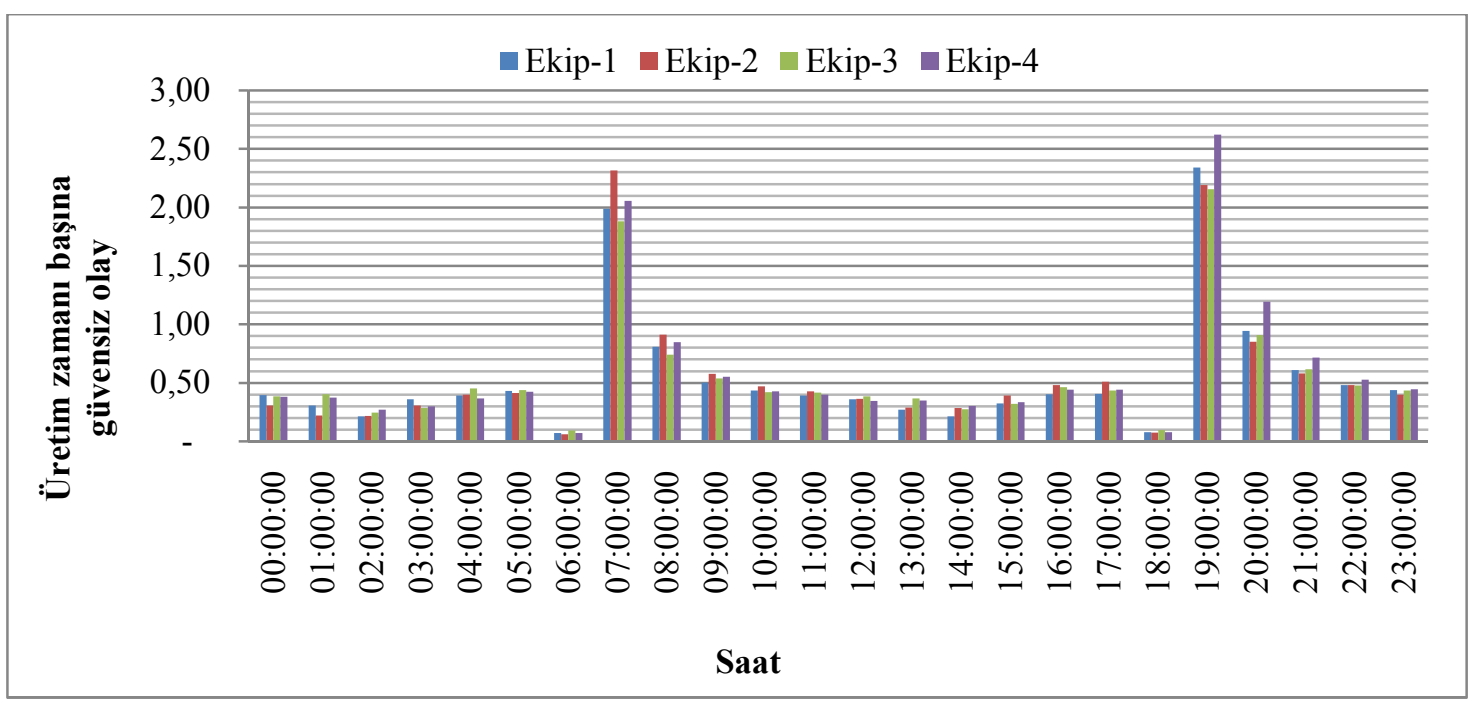

Şekil 2. Üretime elverişli zamana göre güvensiz olay dağılımı

Şekil 2'de görüldüğü üzere, maden ekipmanlarının kullanımı sırasında, kayıt altına alınan güvensiz durumlar, ekipmanın hazır olduğu süre aralığında farklı ekipler için incelenmiștir. Günün özellikle işe başlangıç ve vardiya değişimi olan 7:00 ve 19:00 saatlerinde, daha fazla sayıda güvensiz olay kaydedildiği görülmektedir. Vardiya değişimi sırasında yoğunlaşan güvensiz durumların, işletmenin aralıksız olarak üretimde bulunması ile ilişkili olduğu düşünülmüştür. Durumu daha detaylı şekilde incelemek ve anlamlandırmak amacıyla, veri entegrasyonundan yararlanılmıştır. Vardiya saatleri veri analiz boyutu olarak kullanıldığında, Şekil 3'te görülen dağılım belirlenmiştir.

Güvensiz durumların tüm ekipler için en sık gözlemlendiği zaman aralıkları incelendiğinde, vardiyanın ilk saatlerinde daha fazla kayıt bulunduğu ortaya çıkmıştır. $\mathrm{Bu}$ durumun 
nedeninin ise tüm operatörler için vardiya başlangıcında yaşanan konsantrasyon ve koordinasyon eksikliği olduğu düşünülmektedir. Ancak Ekip-2 için çalışan operatörlerin ilişkilendirildiği güvensiz durumlar daha detaylı olarak incelendiğinde, gündüz vardiyası süresince kayıt edilen daha fazla sayıda durum olduğu tespit edilmiştir. $\mathrm{Bu}$ tespit, derinlemesine analiz gerektiren durumlara bir örnek teşkil etmektedir ve sadece veri görselleştirme araçlarından yararlanılarak derinlemesine analiz yapılmasına ihtiyaç duyulmaktadır.

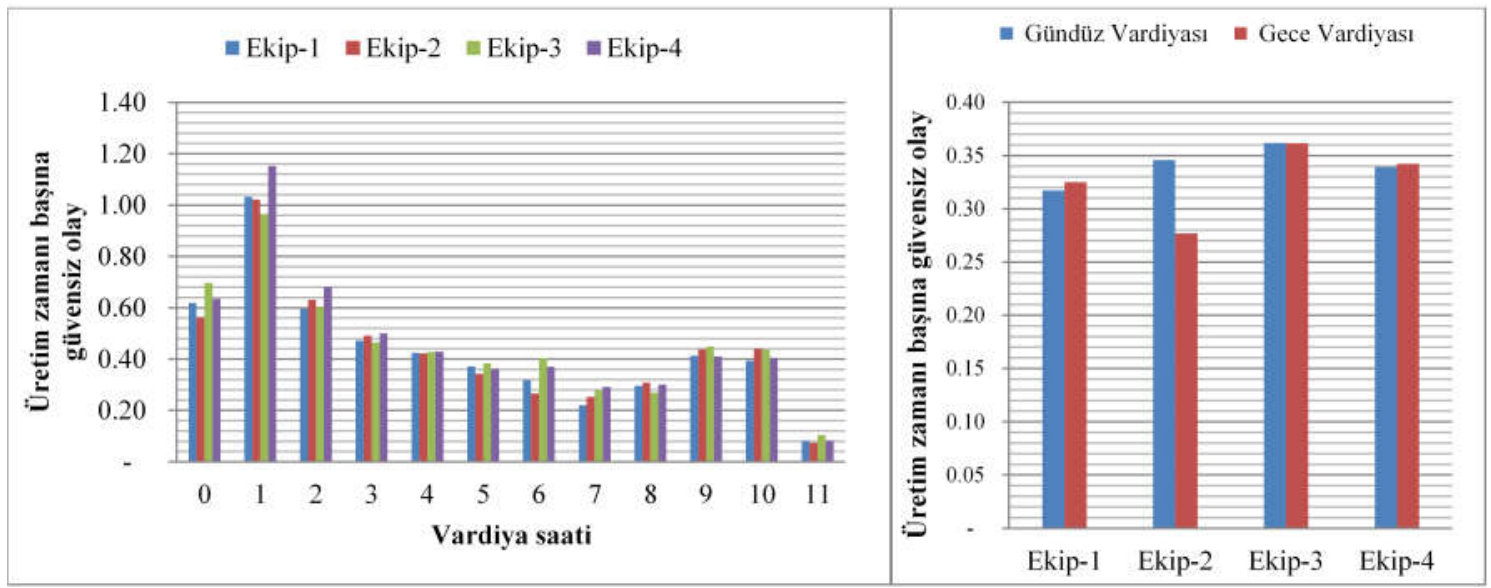

Şekil 3. Vardiya başına üretime elverişli zamana göre güvensiz olay dağılımı

Veri entegrasyonunun sağlandığı altyapılarda, derinlemesine analiz yapılabilmesi için detaydan özete çalışabilecek daha fazla boyut tanımlanması gerekmektedir. Veriyi inceleyerek anlamlandırmaya çalışan mühendisler, entegre edilmiş veriyi görselleştirme sonucu ortaya çıkan karmaşık bilgi karşısında doğru kararlar veremeyebilirler. Bu nedenle, veri madenciliği gibi ileri analiz araçlarına ihtiyaç duyulmaktadır. Şekil 4'te temsil edildiği üzere, mevcut veri daha fazla veri boyutu ve ölçütten yararlanılarak incelenmelidir.

\begin{tabular}{|c|c|c|c|c|c|c|c|c|c|c|c|c|c|c|c|}
\hline \multicolumn{2}{|c|}{ SuM(Events/houf) } & & \multirow[b]{2}{*}{ Ekip } & \multicolumn{12}{|c|}{ Yil / Cevrek } \\
\hline 0.005 & 2.090 & & & 1 & 2 & 3 & 4 & 1 & 2 & 3 & 4 & 1 & 2 & 3 & 4 \\
\hline \multicolumn{2}{|c|}{ SUM/incidents/ 000 read. } & \multirow[t]{4}{*}{ Kömür } & Ekip-1 & 回 & in & E & $\square$ & 国 & $=$ & . & i & $\mathbf{a}$ & & ए & L \\
\hline & 0.2000 & & Ekip-2 & 回 & $=$ & 를 & 뭄 & . & 무 & 물 & ㅂ. & 口 & " & [ & 四 \\
\hline & 0.4000 & & Ekip-3 & 마 & 口 & L & = & " & · & - & a & . & 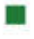 & 口 & 㖵 \\
\hline & $\begin{array}{l}0.6000 \\
0.8112\end{array}$ & & Ekip-4 & 미 & & 밀 & $\mathbf{\square}$ & & $\equiv$ & a & 믈 & $\mathbf{\square}$ & . & 뭄 & L \\
\hline & & \multirow[t]{4}{*}{ Dekapaj } & Ekip-1 & 핌 & 뭄 & $=$ & 표 & " & 픔 & 口 & in & = & 배 & 밈 & \\
\hline & & & Ekip-2 & $=$ & & & - & " & 무 & 口 & 口 & $\mathbf{a}$ & $=$ & = & 口 \\
\hline & & & Ekip-3 & & 口 & & n & " & = & m & 대 & . & & $=$ & ini \\
\hline & & & Ekip-4 & E & E & $\equiv$ & $\equiv$ & 배 & m & 토 & 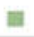 & & 曋 & 몸 & \\
\hline
\end{tabular}

Şekil 4. Çoklu veri boyutları ile incelenen güvensiz durum kayıtları

Ekipler ile ilişkilendirilen güvensiz durumlar incelendiğinde, hangi ekipman ile malzeme taşındığı, kömür üretimi ya da dekapaj işlemi yapıldığ 1 gibi ek bilgiler, yapılan analizlerden çıkarılan sonuçları, daha kapsamlı hale getirmektedir. Farklı veri sağlayan sistemleri entegre etme sirasinda kullanılan mevcut veri boyutları, veriyi zaman gibi ortak bileşenler üzerinde küçük parçalara ayırarak, analiz yapabilme olanağı sağlamaktadır. Ekip-1 için kaydedilen güvensiz durumların 2013 kayıtları daha detaylı incelenmek istendiğinde, özellikle kömür üretimi ile ilgili olan veri boyutları eklenerek, entegre veri seti daha etkin şekilde 
incelenebilmektedir. Örnek olarak sunulan durumlardan birisi, üretime hazır süre içerisinde her ekip ve üretim/dekapaj işlemine göre normalize edilmiş ekipman sağlığı kayıtlarıdır. $\mathrm{Bu}$ tür çok boyutlu bir verinin, sistematik bir yaklaşım olmadan, sağlıklı şekilde incelenmesi mümkün olmayacaktır. Modern maden işletmelerinde kullanılan sistemler göz önünde bulundurulduğunda, veri madenciliği gibi araçlar kullanılmadan anlamlandırılamayacak kadar çok boyutlu ve karmaşık veri setleri bulunmaktadır. Karar verme sürecinde kritik role sahip olan mühendislerin, veri toplama ve raporlama yerine uygun araçlar sağlanarak veri analizine odaklanmaları önerilmektedir.

\section{SONUÇ}

Verilerin analizi, modern madenlerde karar verme aşamalarının ve yönetimin önemli bir bileşeni haline gelmiştir. Güvenlik ve üretim gibi farklı veri kaynaklarının entegrasyonu sayesinde, mühendisler karmaşı ilişkileri kolayca araştırabilir duruma gelmişlerdir. $\mathrm{Bu}$ çalışmanın amacı, madencilik endüstrisinde mevcut olan farklı veri türlerini göstermek ve veri entegrasyonunun bir uygulamasını tanıtmaktır. ABD'de bir kömür madeninden alınan iş sağlığı ve güvenliği ve üretim koşulları ile ilgili veriler zaman, vardiya zamanı, vardiya, tarihler, çalışanlar ve ekipman tipi olmak üzere altı farklı kategoride incelenmiştir. Operatörler için kaydedilen güvenli olmayan olay sayısının, vardiyaların başlangıç zamanlarında meydana gelme olasılığının daha yüksek olduğu gözlemlenmiştir. Bu durumun nedeni, çeşitli durumlardan dolayı oluşmuş olan konsantrasyon eksikliği olarak yorumlanmıştır. Bir ön veri madenciliği uygulaması, ekipman sağlığına ilişkin güvenli olmayan olayların, taşıma türüne göre farklı operatör ekipleri için analiz edilebileceğini ortaya koymuştur. Modern grafik araçları ile bile karmaşık hale gelebilen veriler arasındaki bağlantıları, korelasyonları ve düzenli oluşan kalıpları görsel olarak bulmak için ciddi bir analitik yeteneğe sahip olmak gereklidir. $\mathrm{Bu}$ bahsedilen kalıpları bulmak için veri madenciliği gibi daha sistematik bir metodolojiye ihtiyaç duyulmaktadır. Bu nedenle iş sağlığ 1 ve güvenliği yönetimi ve risk modellemesinde başlatılması gereken en büyük yenilik, veri madenciliği kullanılarak güvenli olmayan veri kaynaklarından entegre veri setleri oluşturmaktır. Madencilik ekipmanlarından toplanan veriler, nesnelerin internetinin (IoT), piyasaya sürülmesiyle daha erişilebilir olmaya başlamış olup, sektörü daha verimli veri toplama ve kullanma yönünde yönlenmektedir. Verilerin kullanımı, modern madenciliğin kaçınılmaz bir bileşenidir ve bu alanda maden mühendislerinin eğitilmesi şarttır.

\section{KAYNAKLAR}

1. Kolonja, L., Stanković, R., Obradović, I., Kitanović, O., Stevanovic, D., Radojicic, M., 2016. A Business Intelligence Approach to Mine Safety Management. 13 ${ }^{\text {th }}$ ISCSM 2016 Belgrade, 1-9.

2. Bonsu, J., van Dyk, W., Franzidis, J-P, Petersen, F., Isafiade, A., 2016. A Systems Approach to Mining Safety: An Application of the Swiss Cheese Model. Journal of the Southern African Institute of Mining and Metallurgy, 116(8), 776-784.

3. Shi D., Guan J., Zurada J., Manikas A., 2017. A Data-Mining Approach to Identification of Risk Factors in Safety Management Systems, Journal of Management Information Systems, 34:4, 1054-1081.

4. Dessureault, S., Sinuhaji, A., Coleman, P., 2007. Data Mining Mine Safety Data, Mining Engineering. 59(8), 64-70.

5. Sanmiquel, L., Rossell, J.M., Vintro, C., 2015. Study of Spanish Mining Accidents Using Data Mining Techniques, Safety Science, 75, 49-55.

6. Sanmiquel, L., Bascompta, M., Rossell, J.M., Anticoi, H.F., Guash, E., 2018. Analysis of Occupational Accidents in Underground and Surface Mining in Spain Using Data-Mining Techniques. International Journal of Environmental Research and Public Health, 15, 462, 1-11.

7. Ruso, J., Stojanović, V., 2012. Occupational Health and Safety Using Data Mining. International Journal for Quality Research, 6(4), 355-363.

8. Cheng, C., Leu, S., Cheng, Y., Wu, T., Lin, C., 2012. Applying Data Mining Techniques to Explore Factors Contributing to Occupational 
Injuries in Taiwan's Construction Industry, Accident Analysis \& Prevention, 48, 214-222.

9. Kniesner, T.J., Leeth, J.D., 2004. Data Mining Mining Data: MSHA Enforcement Efforts, Underground Coal Mine Safety, and New Health Policy Implications. Journal of Risk and Uncertainty, 29(2), 83-111.

10.Gerassis, S., Saavedra, Á., Taboada, J., Alonso, E., Bastante, F.G., 2019. Differentiating Between Fatal and Non-fatal Mining Accidents Using Artificial Intelligence Techniques. International Journal of Mining, Reclamation and Environment, 1-13.

11. Erkayaoğlu, M., Dessureault, S., 2019. Improving Mine-to-mill by Data Warehousing and Data Mining, International Journal of Mining, Reclamation and Environment, 33:6, 409-424.

12. Dindarloo, S.R.R, Siami-Irdemoosa, E., 2017. Data Mining in Mining Engineering: Results of Classification and Clustering of Shovels Failures Data. International Journal of Mining, Reclamation and Environment, 31(2), 105-118.

13. Jianwei, C., Shengqiang, Y., 2012. Data Mining Applications in Evaluating Mine Ventilation System, Safety Science, 50(4), 918-922.

14. Vaught, C., Mallett, L., Brnich, Jr., M.J., Reinke, D., Kowalski-Trakofler, K.M., Cole, H.P., 2006. Knowledge Management and Transfer for Mine Emergency Response. International Journal of Emergency Management, 3(2/3), 178-191.

15. Queensland Mine Safety Framework, https://www.dnrme.qld.gov.au/miningresources/initiatives/qld-mine-safetyframework (Erişim Tarihi: Şubat, 2020)

16. Liu, J., 2019. Using Big Data Database to Construct New GFuzzy Text Mining and Decision Algorithm for Targeting and Classifying Customers. Computers \& Industrial Engineering, 128, 1088-1095.

17. Rogers, W.P., Nelson, M.G., Richins, A., Hodgson, A., 2017. Data Management Best Practices of Complex Socio-technical Systems: A Review of U.S. Mining Safety and Health Management. Proceedings of the 8th International Conference on Sustainable Development in the Minerals Industry, 83-87.
18. Haas, E.J., Ryan, M., Willmer, D.R., 2018. An Examination of Mining Companies' Online Health and Safety Policies: Implications for Improving Risk Management. Journal of Safety, Health, Environmental Research. 14(1), 337-347.

19. Chunmin L., Xin Z., Xin L., 2012. Mine Safetyp. Information Technology in the Framework of Digital Mine, Safety Science, 50(4), 846-850.

20. Kahraman, M.M., Dessureault, S., 2018. Increasing Adherence to Mine Plan Through Data Integration and Process Change, International Journal of Mining, Reclamation and Environment, 32(5), 341-354.

21.Microsoft SQL Server, 2019, https://www.microsoft.com/tr-tr/sql-server/sqlserver-2019 (Erişim Tarihi: Şubat, 2020)

22.Çetinyokuş, T., Gökçen, H., 2008. Bütünleşik Veri Küpü Sistemi (Bvks): Satış Küpü Uygulamas1. Gazi University Journal of Engineering and Architecture, 23(2), 477-484. 